\title{
RUINS AND URBAN CONTEXT: ANALYSIS TOWARDS CONSERVATION AND ENHANCEMENT
}

\author{
E. Romeo ${ }^{1}-$ R. Rudiero ${ }^{2}$ \\ ${ }^{1}$ Politecnico di Torino, DAD, Italy - emanuele.romeo@polito.it \\ ${ }^{2}$ Politecnico di Torino, DAD, Italy - riccardo.rudiero@ polito.it
}

KEY WORDS: Conservation, Enhancement, Theatre, Amphitheatre.

\begin{abstract}
:
The paper presents the results of a study of classics theatres and amphitheatres in Europe and in the Mediterranean basin. The analysis started from the mapping of the Greek and Roman cities and has been focused in particular to the study of the transformations of these cities from the Middle Age to today, carried out through cartographic surveys, archival investigations and direct analysis. This process has led to understanding the different kinds of reuse that the theaters and amphitheatres have undergone throughout the centuries. Then, by comparing the historical city maps to the current ones (e.g. the maps of urban land registers), the archaeological traces of theatres and amphitheatres still incorporated in the current urban buildings have been located. Finally, a survey of the current situation has allowed identifying the material consistency and morphological characterization of these ancient artifacts.

The process led to the proposal of strategies for the conservation and enhancement of ancient entertainment buildings, that respect both the archeological elements and the successive stratification that characterize today our historical cities.
\end{abstract}

\section{Premises for a correct approach to conservation ${ }^{1}$}

The architectural heritage of the classical age, present in Italy and Europe, but also in all of the countries surrounding the Mediterranean basin, has been the object of various phenomena through the centuries, which have determined its abandon or the continuity of its use, its transformation, or its partial loss of integrity.

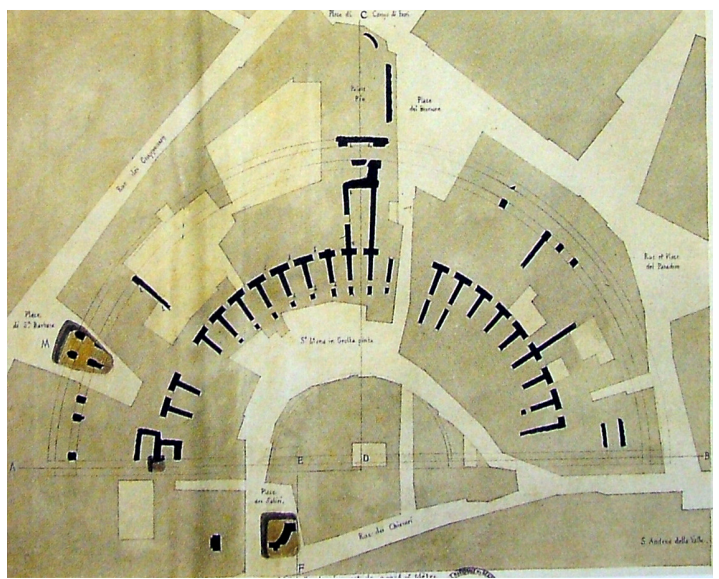

1. Rome, Pompey's theater: topographic survey of the late XIX century.

Entertainment buildings in particular (theatres, amphitheatres, odeia, circuses, stadiums, hippodromes), following destructive events or simply because of the discontinuation of their use, have reached us in a state of ruin; this often after going through transformations, conversions to new uses, reparations of various kinds of damage, restoration or consolidation interventions, adaptations to new stylistic standards: processes which on one hand hinder the recognition of those characters typical of

\footnotetext{
${ }^{1}$ This paragraph in particolar has been written by Emanuele
} Romeo classical architecture, but on the other have guaranteed the survival of these buildings through continuous integration in the most varied urban activities.

Today this heritage, situated at the heart of historical cities, is mostly seen as a tourist attraction and as such subjected to constant attention. However such actions often alter the documentary value of these structures, as appropriate documentation techniques are not yet put in use in order to preserve them with their original architectural characteristics and, in particular, their subsequent stratifications ${ }^{2}$.

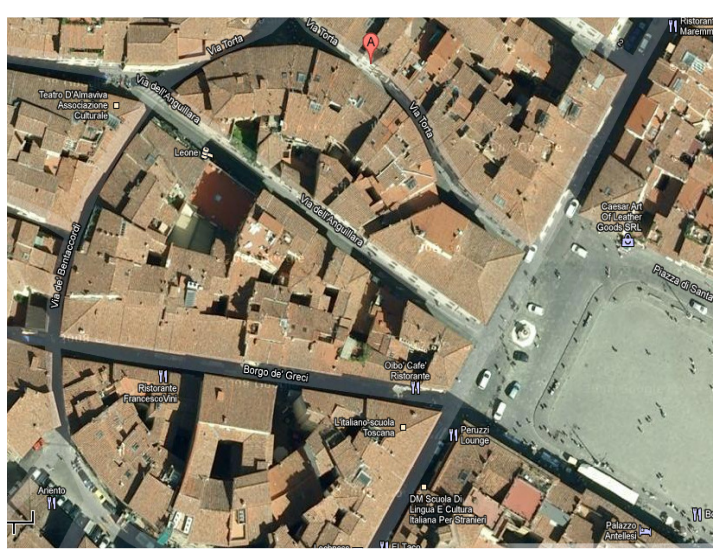

2. Florence, Roman amphitheater. satellite view of the Santa Croce district.

The relationship between context and architecture lasted centuries, even through changes in the function of these entertainment buildings, which became the focus of

\footnotetext{
${ }^{2}$ For further research cf. Brandi, C., 2001. Il patrimonio insidiato. Scritti sulla tutela del paesaggio e dell'arte; a collection of essays edited by M. Capati, Roma 2001. Settis, S, 2002. Italia S.p.A. L'assalto al patrimonio culturale. Einaudi, Torino. Erbani, F., 2003. L'Italia maltrattata. Laterza, Bari; and also: Sgarbi, V., 2003. Un paese sfigurato. Viaggio attraverso gli scempi d'Italia. Rizzoli, Milano.
} 
residential clusters or strongholds for the protection of the same cities. This function, through subsequent transformations owing to well-known modern age adaptations, remained mostly unchanged until, with the rediscovery of classical antiquity, archaeological excavations and subsequent restoration interventions threatened these complex stratifications ${ }^{3}$.

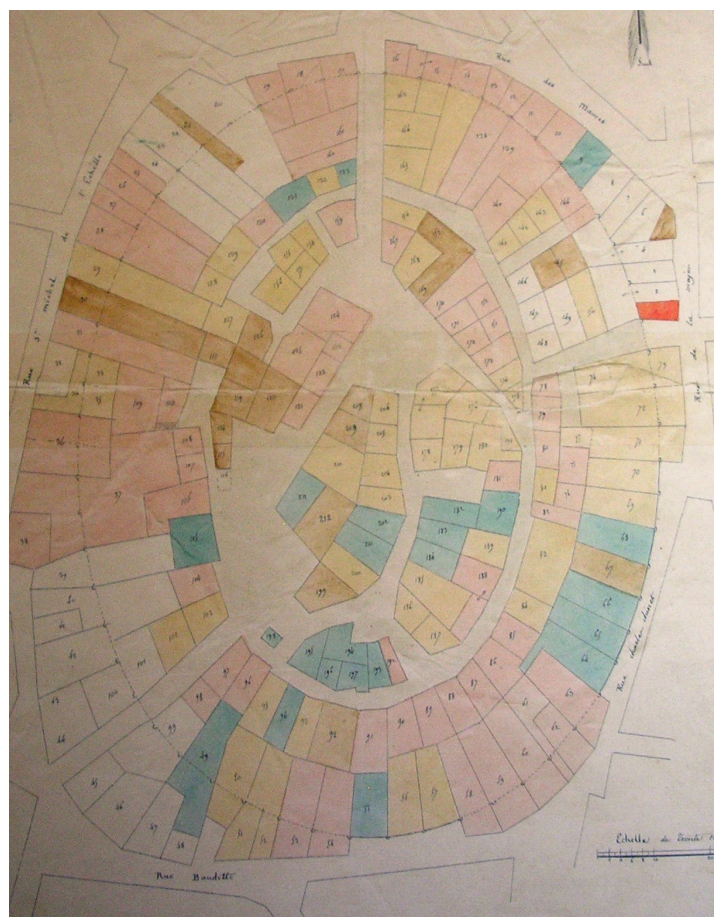

3. Arles, the amphitheater with an indication of the consistency of the building before demolition of the Nineteenth century

On the basis of these premises, this contribution introduces the results of a research that aims for the conservation of this heritage. The suggested valorisation strategies, while respectful of contemporary requirements, promote a touristic fruition plan that is compatible with a heritage that can be considered both architectural and urban, and that follows the transformation dynamics that have always guaranteed a close bond between building and city.

The research on this topic ${ }^{4}$, partly summarized in this essay, introduces a few considerations on the extent of archaeological heritage in urban contexts, analyzing its current preservation status, suggesting advanced survey techniques, and finally suggesting new valorisation strategies.

Ancient entertainment buildings can be found today in many cities but also throughout the territory and can be, in our opinion, divided in at least four categories based on not only the historical events that have determined their conservation, but also on their use throughout history, and on

\footnotetext{
${ }^{3}$ Scazzosi, L. Paesaggio e Archeologia, in Kirova, T. (edited by), 2007. Conservation and restoration of the archaeological heritage, Edizioni AV, Cagliari, pp.77-81. Tosco, C., 2007. Il paesaggio come storia. Il Mulino, Bologna.

${ }^{4}$ Romeo, E., 2008. Problemi di conservazione e restauro in Turchia. Appunti di viaggio, riflessioni, esperienze. Celid, Torino; Romeo, E., 2007. Instaurare, reficere, renovare. Tutela, conservazione, restauro e riuso prima delle codificazioni ottocentesche. Celid, Torino.
}

the degree of interest that they have raised in the past, especially in the decades between the $20^{\text {th }}$ and $21^{\text {st }}$ centuries: in the first group are those structures found in locations or archaeological sites well known to critics; to the second group belong those buildings that can be formally recognized in urban areas boasting Roman or Greek foundations; in the third group are entertainment buildings still present (in urban areas but also other contexts) but only recognizable through traces or whose structure corresponds to current building or urban systems; the fourth group, finally, gathers those structures (mostly not adequately researched) which are located throughout the landscape: these are more or less preserved, frequently prove to be abandoned, and are almost never the object of valorisation strategies.

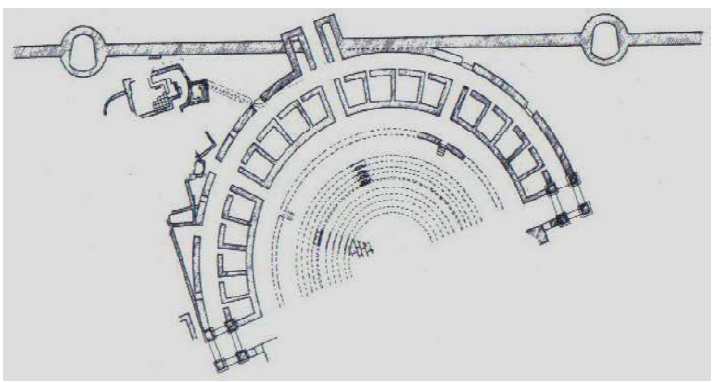

4. Saepinum, the ruins of the theater in the Twentieth century

Furthermore, these buildings show subsequent stratifications that on one hand have guaranteed their survival, but on the other, by not showing the typical classical architectural characters, haven't raised enough interest even while representing a potential cultural resource as much as the other categories ${ }^{5}$.

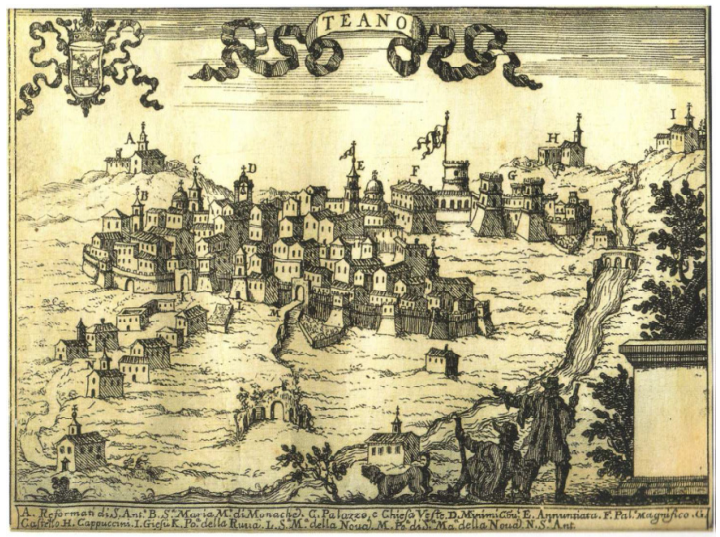

5. Teano, perspective view of G.B. Pacichelli, (1703). In the foreground are the ruins of the theater

Up to now valorisation practices have in fact favoured structures located in traditionally acknowledged archaeological areas which have maintained, even though in ruins, an authentic "classical" character by not showing stratifications owing to reuse. The same cultural influences have also too often suggested restorations and operations of "liberation" from stratifications on theatres and amphitheatres (both in archaeological sites and in urban contexts of roman foundation) in order to recover the original image of the

\footnotetext{
${ }^{5}$ Treccani, G. P., 2010. Aree archeologiche e centri storici. Costituzione dei Parchi archeologici e processi di trasformazione urbana. Franco Angeli, Milano.
} 
monument, thus endorsing the loss of valuable layers of history which had been collected on these structures.

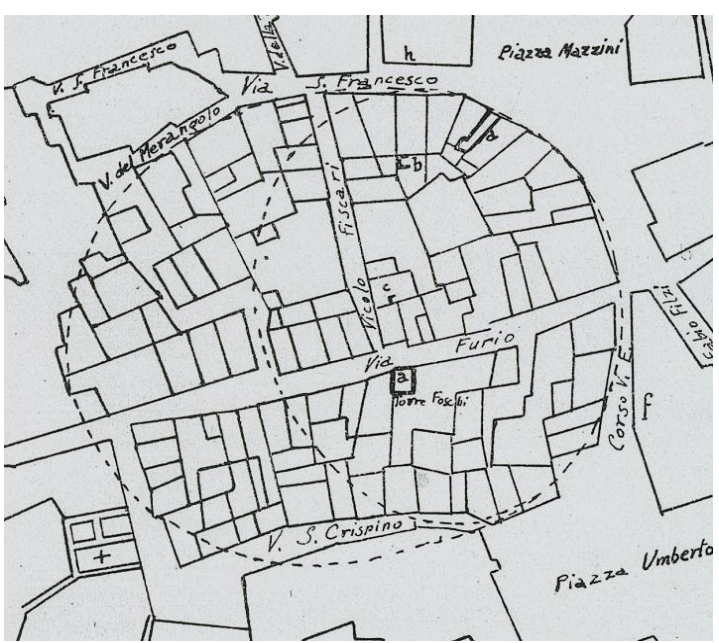

6. Velletri, identification of the theater in the town center

On the other hand, those complex elements resulting from successive stratifications haven't yet been through a recognition process, mostly because of the lack of understanding for these same centuries-old processes ${ }^{6}$.

Considering then the growing interest for cultural heritage conservation in Europe and in extra European countries, and the new initiatives in the field of archaeological heritage conservation, there follows a need for improved instruments for its study and valorisation. This includes, after the identification of the structures inside urban aggregates and the analysis of their transformation processes, the development of instruments for the interpretation of these classical testimonies in the landscape, and the creation of befitting promotion strategies.

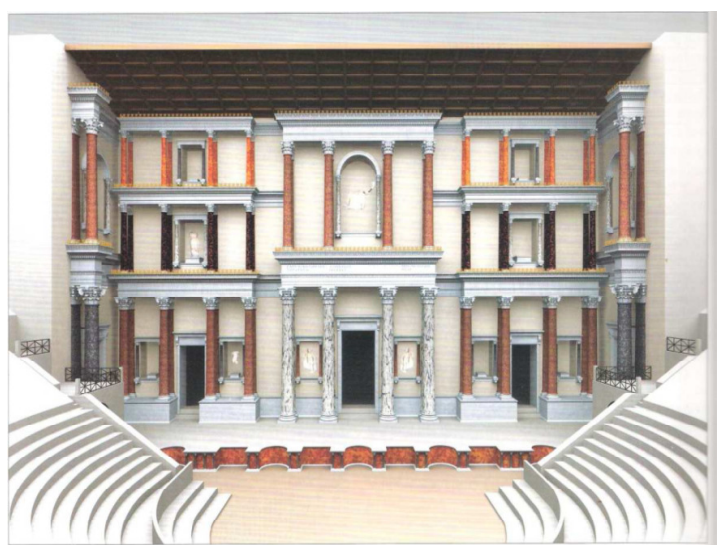

7. Teano, Three-dimensional model of the front scene according to the hypothesis of Heinz Jurgen Beste

In fact, many cities in Italy and in other countries of the Mediterranean basin have, in the last few years, been the object of studies that have sometimes led to programmes for archaeological heritage valorisation. The objective, then, is to include ancient entertainment buildings in a national and international conservation program, in part already underway. The instruments for the study of these structures, when present, are still excessively bound to the traditional survey

\footnotetext{
${ }^{6}$ Dezzi Bardeschi, M., 1993. Per la tutela preventiva delle
} risorse archeologiche, in "Tema" n.3, pp.32-34. and graphical restitution methods, which are unsuited to point out those aspects that would contribute to the understanding of such a wide and interesting heritage ${ }^{7}$. Also, in no example among those that have been studied, and on which conservation strategies have been started, much attention has been shown to the context in which the structures are located: on the contrary valorisation strategies aimed to touristic use have frequently led to the devastation of the "city-monument system" as well as to the isolation of the ruins with consequent loss of their documental value.

The analysis started by mapping the cities founded in the Greek and Roman periods. Cartographic, archival and direct study then focused on these cities' transformations from the Middle Ages onwards. From here it was possible to understand the various uses that have involved theatres and amphitheatres through the centuries. Then a comparison between the historical and current cartography (in particular the land registers) highlighted the "archaeological evidences" absorbed by modern buildings. Finally a survey of the current situation reported the material and morphological state of the ancient artefacts. All of this allows the proposition of conservation and valorisation strategies for these recreational and theatrical buildings, with respect to archaeological heritage but also to the consecutive stratifications which characterize today our historical cities.

\section{Analysis aimed at conservation and valorization ${ }^{8}$}

The study of ancient entertainment buildings calls for a complex documentation process which, starting from the building's origins, must take into account all phases of its history including the most recent ones, namely those that have led to that fascinating relationship between mankind's history and the continuous and relentless alteration of the ruins.

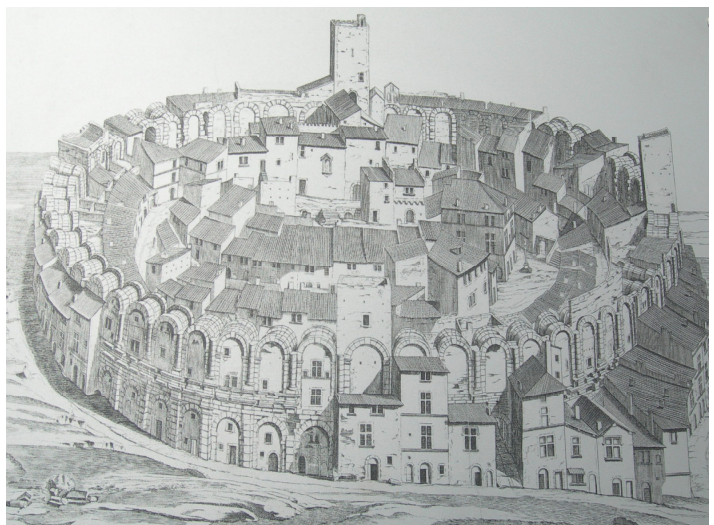

8. Arles, hypothesis of the amphitheater during the XVII century

Firstly, then, it is necessary to identify, through topographic maps, all the known buildings within urban

\footnotetext{
${ }^{7}$ Cruciali Fabozzi, G. Il rilievo per la conservazione: dalla raffigurazione dell'architettura alle "carte tematiche" della fabbrica, in "XY dimensioni del disegno" year V n.11-12, pp.135-141.

In particular this paragraph was written by Riccardo Rudiero
} 
contexts, including also those which show later stratifications ${ }^{9}$.

It is necessary to verify the state of the legislation and the existence of conservation policies extending to the archaeological structures, their context and especially to their stratifications. The existing graphic documentation must also be verified and, if inadequate, integrated with new surveys carried out with current systems and technologies.

The identification of classical permanences in historical cities is also essential, together with the study of their later uses and integration with political, economical, social dynamics.

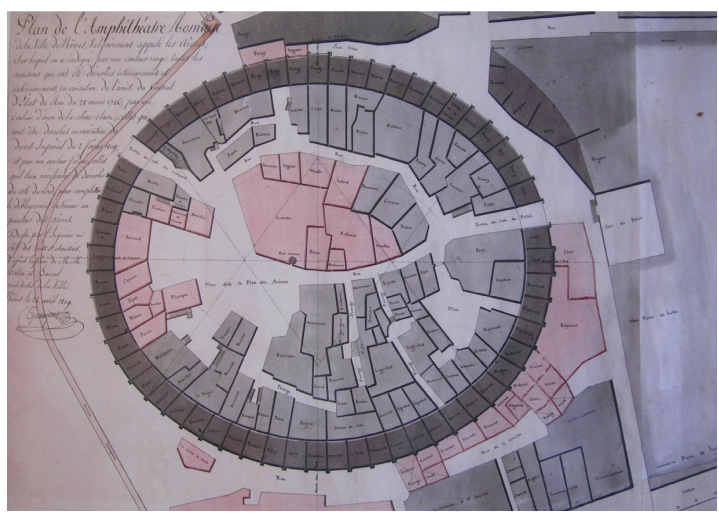

9. Nîmes, plan of the amphitheater designed in 1809 by Grandent with houses demolished or remaining to be demolished

A historical register of the buildings must be compiled identifying the transformations owing to functional adaptations, and exposing the more recent incongruous elements.

There follows, unavoidably, the study of architectural elements and technological solutions pertaining to later additions, and a verification of their efficiency.

Furthermore, for those theatres and amphitheatres which are still in use, an analysis of current functions and of the urban context is essential, and must focus on the compatibility between conservation of the structures, landscape preservation, and fruition.

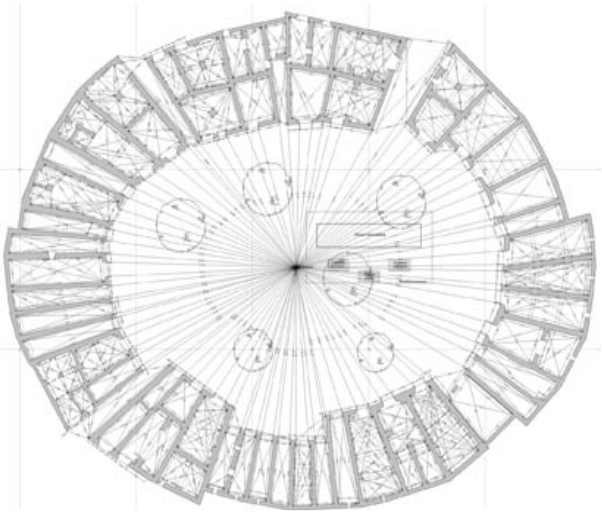

10. Venafro, cadastral map of the amphitheater with an indication of the individual properties

\footnotetext{
${ }^{9}$ The methodological basis taken as reference in this section refers to the one drawn up by Mario Dalla Costa in his volume Il progetto di restauro per la conservazione del costruito, Celid, Torino 2000.
}

Another determining factor is the creation of thematic tables related to the state of conservation of the structures and, in order to facilitate their study, the identification and cataloguing of possible finds kept in museums and ascribable to these urban systems and architectures.

Finally, for the development of a correct conservation policy, it is necessary to consider the drafting of a Charter with both methodological guidelines (in order to define a reference point of typologies, requirements and priorities for analysis procedures), and conservation and valorisation procedures. The Charter will contain recommendations on conservation - including restoration, consolidation and maintenance projects - but also programmes for urban and territorial redevelopment and proposals for compatible reuse.

This document, with reference to the indications contained in the more recent national and international Charters on archaeological and urban heritage restoration (in particular the international Siracusa Charter for the conservation, fruition and management of the ancient theatrical architectures of 2004) $)^{10}$, will focus on different specific questions, as for example the recognition of the cultural value of these structures, operating procedures on materials and architectural elements, permanence of formal and functional characters, relationships with the urban and territorial context, connections with the current socio-economic realities.

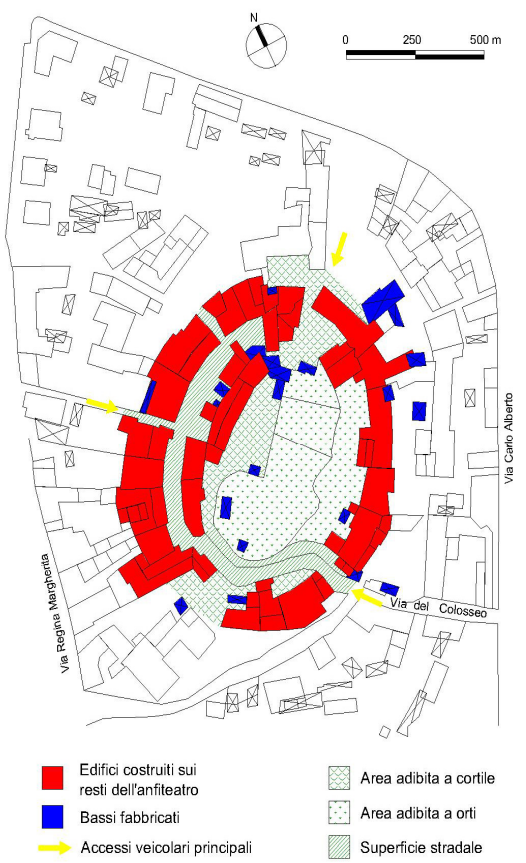

11. Pollenzo, the amphitheater with an indication of the current building consistence

Finally, a last objective, in terms of valorisation and promotion, could be that of creating a series of guidelines (scientifically correct but accessible to everyone) to support the interpretation of this widespread heritage, with strategies that can be relevant on a national (for each single country) and international (for the whole Mediterranean basin) level.

10 Carta di Siracusa per la conservazione, fruizione $e$ gestione delle architetture teatrali antiche (Siracusa 2004). The document was written in occasion of the II International Conference Teatri antichi nell'area del Mediterraneo, Siracusa 13-17 october 2004 
Particularly it would be useful to: plan themed itineraries for the fruition of archaeological remains; publish maps, historical data, virtual reconstructions of theatres and amphitheatres that can highlight the different transformations and an abacus of reemployed elements found in the structures or in the wider urban context; create interactive cartographies connecting the diverse fields of study and promoting the accessibility of data and information at different scales.

Thus, the use of technologically advanced instruments, combining ease of use with scientific precision, seems unavoidable: a useful medium could be the GIS systems which, by mapping a remarkable quantity of data and proving to be easily consulted through the internet, would enable every kind of user to access historical and territorial information.

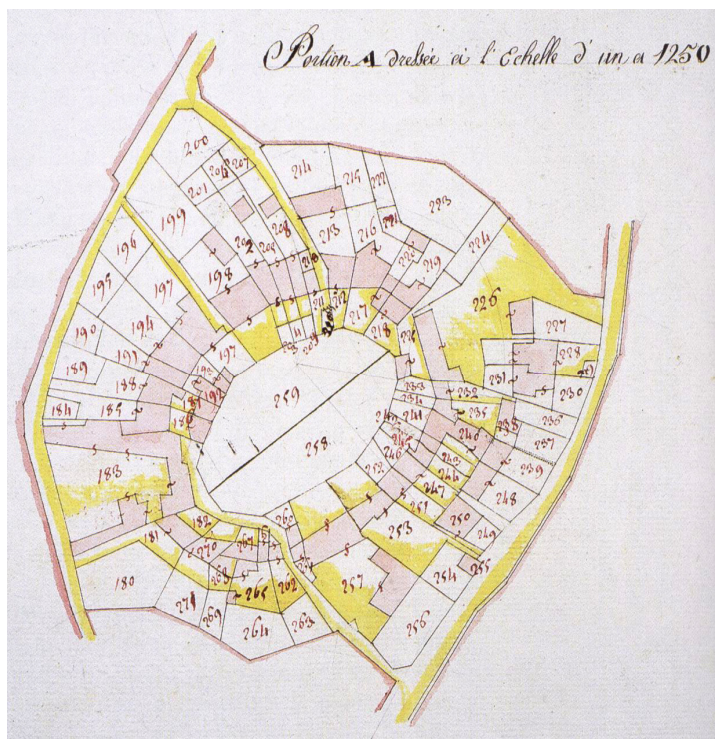

12. Pollenzo, the amphitheater as it appeared in the Napoleonic cadastre

Another aid to the study of ancient ruins can originate from modern technologies used for surveys which, as a basis for understanding the monument, can be effectively used in the valorisation phase. For example, the result of surveys carried out with advanced methods and instruments, together with the consequent three-dimensional representations astoundingly precise in their description of the material consistence of the architectures - can be employed in valorisation, both in the physical environment of the structure, and through virtual channels through the web.

So as not to incur into the pre-eminence of the evocative impact of a virtual reconstruction over its precision or into excessive technicalities to the detriment of the actual contents (the so-called "Cinecittá" and "Star Wars" syndromes), threedimensional reconstructions must avail themselves of restoration's disciplinary rigorousness, with that which is defined Virtual Restoration and which, in the archaeological field is called Virtual Archaeology. Both these fields, related to cultural heritage, have an innate didactic role, allowing for the reconstruction of monuments, cities, and landscapes «with the objective of communicating cultural heritage in a way that is efficient, quick and repeatable» ${ }^{11}$, and also act as a tool for the verification and synthesis of analytical data.

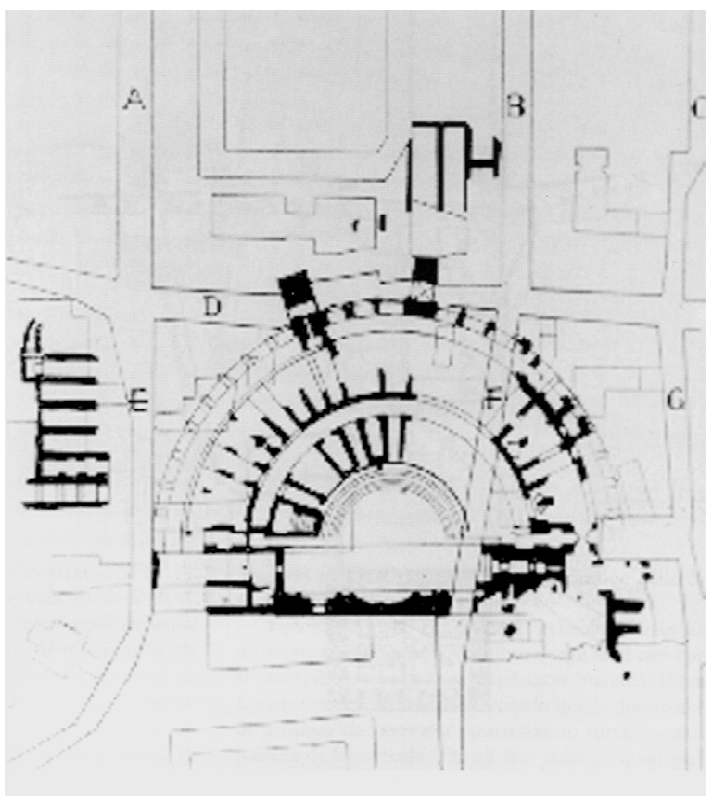

13. Napoli, the theater on a map of the late eighteenth century

Every time a correct conservation program is aimed for, it is then necessary that marketing aspects are supported by rigorous historical and scientific evidence and, as a consequence, the instruments used are also the basis for the valorisation: thus, the applications of Virtual Restoration and Virtual Archaeology represent the equilibrium between disciplinary accuracy and didactic and marketing potential.

In conclusion, it is possible to declare that only by implementing strict methodologies and, when necessary, advanced technologies, a correct conservation of ancient entertainment buildings can be attained. These structures, through their transformations, can renew and strengthen the correlations with the surrounding territory and landscape, becoming focal points on which memories of the past are gathered: centuries, historical events, economic and social processes of a community or of an entire society.

\footnotetext{
${ }^{11}$ Limoncelli, M., 2012. Il restauro virtuale in archeologia. Carocci editore, Roma, p. 26.
} 